\title{
A Dialectical Tier Within Reason
}

\section{AMY J. OHLeR}

\author{
McMaster University
}

\begin{abstract}
The first part of this essay argues that the specification of rationality operating in Manifest Rationality does not allow for the inclusion of the dialectical tier as a necessary component of a rational product. It next considers Perelman's conception of "reasonableness" as an alternative to Johnson's structural sense of rationality. Adopting a contextually rich conception of rationality, like that of Perelman, allows Johnson to insist that a rational product must consist of both an illative core and a dialectical tier.
\end{abstract}

Résumé: La première partie de la dissertation prouve que la stipulation de la rationalité qui fonctionne dans Manifest Rationality ne permit pas l'inclusion du niveau dialectical ("dialectical tier") comme partie nécessaire d'un produit rationnel. Ensuite, elle examine la conception du "raisonnable" de Perelman comme contre proposition du sens de la rationalité de construction de Johnson. S'il adopte une conception de la rationalité riche de contexte, comme celle de Perelman, Johnson peut insister qu'un produit rationnel doit se composer d'un coeur d'inférence ("illative core") et d'un niveau dialectical ("dialectical tier") tout les deux.

Keywords: dialectical tier, manifest raitonality, Perelman, rationality, reasonableness, rhetoric.

\section{Introduction}

It is my contention that in Manifest Rationality: A Pragmatic Theory of Argument, Ralph Johnson operates with a specification of rationality that does not allow for the generation of one of the features essential to his definition of argument, the dialectical tier. The assumption underlying this paper is that when discussing the nature of rational argumentation, we should have at our disposal a conception of rationality in argumentation that is rich enough to account for all those elements of an argument that we want to say make it rational. It is a virtue of any theory that we be able to generate our criteria for what counts as rational out of the specification of rationality in use. In the first part of my paper, I make the case that given Johnson's specification of rationality, the inclusion of the illative core is necessary for an argument to count as rational, but that the same cannot be said for the dialectical tier. Johnson's specification of rationality does not provide justification for the inclusion of the dialectical tier as an essential component of a rational argument. The next part of the paper turns to Chaim Perelman's concep- 
tion of rationality in argumentation, according to which "reasonableness" as a candidate for a richer conception of rationality in argumentation, one that provides the means to justify the dialectical tier as a necessary component of a rational product. In the closing section, I briefly consider Johnson's proposed criteria for the evaluation of arguments. I contend that a contextually rich conception of rationality in argumentation like that of Perelman offers the means to generate Johnson's normative criteria out of the conception of rationality in play. I propose a different conception of rationality for the theory of argumentation put forth in Manifest Rationality, arguing that Johnson's structural sense of rationality combined with Perelman's contextualized sense of reasonableness seems to get at the truth in the claim that "argumentation is rational."

\section{Johnson on Rationality and Argumentation}

Johnson asserts "the central thesis of [Manifest Rationality] is that to properly understand the practice of argumentation, we must view it as an exercise in manifest rationality" (Johnson 2000, 144). What this means is that a good argument is a rational product and that the product must also appear to be rational. Although Johnson's main interest is in the product of argumentation, his position is that we must understand the product as arising out of the practice. Hence, the theory of manifest rationality takes both the argument as a product and the practice of argumentation into account. Both the product and the practice play an important role in comprising Johnson's theory of what counts as rational in argumentation.

Johnson states that "we engage in the practice of argumentation because we wish to persuade someone of something, and to do so rationally" (ibid., 148). According to Johnson, the fundamental purpose of argumentation is rational persuasion, defined as "persuad [ing] the Other to accept the conclusion on the basis of the reasons and considerations cited, and those alone" (ibid., 150). The purpose of argumentation as rational persuasion informs Johnson's definition of argument. As he puts it, "because I wish to persuade the Other by reason, I recognize that the claim I make must be supported by reasons or evidence of some sort" (ibid., 150). Hence the premise-conclusion structure of the product of argumentation, the 'illative core' of an argument. However, the illative core is not enough to capture the full sense of the product as arising out of the practice of argumentation. "If argumentation is to be an exercise in rationality, the arguer has an obligation to take into account the positions of others who have also taken a rational position because to fail to do so would not be rational. More important, to fail to do so would not be in keeping with the very nature of argument as a display of rationality. If the arguer takes seriously the positions of others and in the course of his own argument addresses himself to them, the result is a display that not only is rational, but is also one that appears to be rational" (ibid., 151). Taking into account the positions of others in the form of objections or alternative positions comprises the second level of Johnson's definition of argument-the dialectical 
tier. An argument, if it seeks to persuade an audience rationally must be comprised of both an illative core and a dialectical tier. What's more, the inclusion of the dialectical tier exhibits "the character of rationality" (ibid., 152). As Johnson puts it, "arguments... are outcomes within the practice [of argumentation] that are dialectical in nature and characterized by manifest rationality" (ibid., 178).

What is required, then, is to get clear on what Johnson means by 'rationality.' Once the concept of rationality is discussed, I will return to the components of his definition of argument, the illative core and the dialectical tier, in light of this definition of rationality. I hope to show that when Johnson claims the necessity of the dialectical tier in understanding an argument as a rational product, he must mean more than his definition of rationality allows.'

Now then, to return to the illative core and the dialectical tier in light of this specification of rationality. Johnson identifies three features of the practice of argumentation that are essential for understanding what counts as an argument. The practice of argumentation is teleological in the sense that its purpose is rational persuasion. Given that rational persuasion has been defined as the attempt to persuade an audience on the basis of the reasons offered, the inclusion of the illative core as a necessary component of a rational product fits with the specification of rationality as the disposition to and action of using, giving, and/or acting on the basis of reasons. That is to say, an argument must possess an illative core in order to be a rational product. However, it is not altogether clear that the inclusion of the dialectical tier as a component of an argument as a rational product fits as easily with this understanding of rationality and the definition of rational persuasion.

According to Johnson, because the purpose of argumentation is rational persuasion, the dialectical tier is also required. Because the practice of argumentation presupposes controversy, the audience will know "that there will likely be objections to the arguer's premises" (ibid., 160). Typically, an arguer anticipates and defends herself against common objections or alternative positions in the course of arguing. "If the arguer does not deal with the objections and criticisms, then to that degree, the argument is not going to satisfy the dictates of rationality" (ibid., 160). Typically, the audience will also be aware of common objections and criticisms to a position. "Hence, if the arguer wishes to persuade Others rationally, the arguer is obligated to take account of these objections and opposing points of view" (Johnson, 2000, 160). However, can the necessity of responding to objections and alternative positions be understood as arising out of Johnson's specification of rationality? If we take his understanding of rationality to be "the disposition to, and the action of, using, giving, and/or acting on the basis of reasons" (ibid, 161) literally, then it seems we must accept the dialectical tier as a necessary component of rational argumentation because of its inclusion of more reasons at play. The dialectical tier in considering criticisms and objections must be understood as considering reasons for or against the premises used to argue for the conclusion, and alternative positions construed as reasons not to accept the con- 
clusion, if we are to attempt to understand the necessity of the dialectical tier as following from Johnson's specification of rationality. On his specification of rationality, the inclusion of the dialectical tier is necessary because it puts more reasons into operation. If the quantity of reasons considered is what makes one argument more rational than another, then Johnson has not failed in generating the requirements for a rational product out of his specification of rationality.

However, it seems wrong-headed to suggest that one argument is more rational than another by virtue of the number of reasons in play. At the very least, it seems we should want to say something about the quality of the reasons put into play. Here I do not mean 'quality' in a normative sense, but rather understand "quality" to indicate some aspect of the reasons considered that makes it rational to include them. Johnson rightly notes the role of the audience in determining what objections and alternative positions are to be discussed, also included in his discussion of the dialectical feature of argumentation. My only claim is that Johnson's specification of rationality does not rule out the kind of interpretation I have just presented. That is, a rational product considers many reasons. This may very well be something we want to accept. But I would also argue that we want our conception of rationality to tell us what sorts of reasons need to be considered. To be charitable, it is not at all clear that this 'quantity of reasons' is the conclusion Johnson wants us to draw. Consider his claim that "to ignore them [objections and opposing points of view], not to mention them, or to suppress them-these could hardly be considered the moves of someone engaged in the process of rational persuasion" (ibid., 160). It is not at all clear that Johnson wants us to accept the above on the grounds that not enough reasons are considered by the argument. It seems that with this remark, Johnson is operating with a different sense of "rational', perhaps as a value term. It seems that another, richer understanding of rationality is at play here, rather than just the giving and receiving of reasons. Rather, the actualities of the Other, the audience, or the discussion at hand must inform the content of the dialectical tier. My claim here is that content more than structure is what Johnson may be driving at. The importance of the content of the dialectical tier is diminished if we construe rationality as Johnson has specified. I will return to this point shortly. For the sake of being thorough, I want to briefly mention Johnson's second feature of argumentation-that argumentation is dialectical - in light of his conception of rationality.

According to Johnson, "an exchange is dialectical when, as a result of the intervention of the Other, one's own logos (discourse, reasoning, or thinking) has the potential of being affected in some way" (ibid., 161). It is possible to understand the actual response of the Other in the form of objections, criticisms and opposing points of view resulting in a better argument, "a more rational product" (ibid., 161) in light of Johnson's specification of rationality, as putting more reasons into play, because here it is the actual reactions of the Other which must be addressed. Johnson's conception of rationality works in answering actual objec- 
tions and criticisms that require a response in order for an argument to persuade the audience. However, there is a difference between the actual or real responses of the other as compared to those the arguer attempts to anticipate in constructing an argument. This is a point that must be emphasized, given that Johnson has expressed that the main focus of his theory of argument concerns texts. While Johnson's conception of rationality works for actual discussions, it is not at all clear that it will work for the construction of texts.

Johnson identifies the final feature of the practice of argumentation as manifest rationality. In the preamble to his explication of manifest rationality, Johnson discusses some aspects of the connection between argumentation and rationality. I will briefly discuss each here, in light of his specification of rationality. Argumentation embraces rationality, requiring "that nothing be accepted but what is shown to have reason [or perhaps more charitably, reasons] behind it" (ibid., 162). Second, argumentation depends on mutual rationality, a claim that is uncontroversial-we need a partner who also shares the disposition to use, give, and act on the basis of reasons. Third, argumentation increases rationality, resulting in participants that are more rational, in that the participants in the practice of argumentation become better reasoners. Lastly, argumentation exhibits rationality in the public performance of reasoning. Interestingly, rationality is also "the glue that binds" (ibid, 163) argumentation and rhetoric. The rhetor is rational, using reasons to support her position. However, "what separates rhetoric from argumentation is that the latter is bound by the requirement of manifest rationality" (ibid., 163). The rhetor may ignore objections to her argument "if ignoring the objection will lead to a more effective communication, and if doing so is rational" (ibid., 163). The most charitable interpretation suggests that here Johnson has in mind an Aristotelian conception of rationality, where what is an effective means to our present goal is what it is rational to pursue. While rhetoric is also a rational activity, argumentation proper is bound by Johnson's third and final feature of the practice, manifest rationality.

"To say that the practice of argumentation is characterized by manifest rationality is to say that it is patently and openly rational" (ibid, 163) to all those involved, whether arguer, critic or audience. The participants "agree to do nothing that would compromise either the substance or the appearance of rationality" (ibid., 163). This may be best understood as stipulating that all parties involved agree to accept nothing that is not supported by reasons. "This clothing of rationality is what makes argumentation more than just an exercise in rationality. Manifest rationality is why the arguer is obligated to respond to objections and criticisms from others and not ignore them or sweep them under thecarpet" (ibid, 164). To not answer to objections and criticisms "would not only not be rational; it would not look rational" (ibid., 164). The requirement of manifest rationality is this: in order for argumentation to be rational, it must appear to be rational. Argumentation can display its rationality by responding to objections, criticisms and alternative points 
of view. And here, Johnson seems to be in keeping with his specification of rationality. Here, the bulk of reasons considered results in a more rational product for "the requirement of manifest rationality explains why the arguer must respond even to criticisms that are believed (or known) to be misguided" (ibid., 164). We may of course ask, who believes or knows these criticisms to be misguided? To have to respond to criticisms believed or known to be misguided is in one important sense of the word quite irrational. It must be rather that the Other is unaware that the criticisms are misguided. Further in this section Johnson appears to restrict the above claim by referring to "well-known objections" (ibid, 164). As I have argued above, it would be much preferred if our conception of rationality itself could provide the means for including the dialectical tier in content, beyond the structural requirement of considering as many reasons for and against a position as possible. Johnson also seems to be aware of this point. In a footnote he states that "the idea of rationality alone cannot illuminate the practice of argumentation; without the rationality being manifest, there cannot be the common knowledge required for the practice" (ibid., 164). To this I absolutely agree. It is exactly this common knowledge that must be privileged if we are to understand the importance of the dialectical tier, what drives the requirement that rationality be made manifest. However, to do so, we need a richer conception of rationality than simply the giving and receiving of reasons. What we need is a conception of rationality that privileges appeal to common knowledge itself as a rational appeal. I turn now to the work of Perelman as offering one alternative conception of rationality that may provide an argument for the acceptance of appeal to common knowledge as a rational component of argumentation.

\section{Perelman, the Rational, and the Reasonable}

Perelman famously offers a distinction between the terms 'rational' and 'reasonable.' This distinction should be understood as providing a justification of argumentation as a rational activity. I will first briefly explain what Perelman takes the "rational" to be and by contrast, discuss his characterization of the "reasonable." I hope to show that for Perelman, the task is not to show that the rational and the reasonable are complete, separate entities. Essentially, Perelman's explication of what counts as reasonable is a theory of rationality, the mode of rationality that is to be found in the practice of argumentation. That is to say, Perelman's distinction between the rational and the reasonable (in terms of the truth criterion and method of each) is intended as an extension of the concept of reason, such that the reasonable is recognized as rational. To engage in argumentation for Perelman is, quite simply, to be rational. When Perelman outlines his distinction, he is telling us how rationality is at work in argumentation. To engage in argumentation is to be rational in the mode of reasonableness. What will count as reasonable is function of the historical and contextual concerns of the audience as imagined by the speaker. To be rational in argumentation, then, is to recognize the contextual and historical 
situation of the audience. It is this aspect of Perelman's conception of reasonableness that may help flesh out Johnson's conception of rationality and provide grounding for the inclusion of the dialectical tier as a necessary component of a rational product.

Perelman begins his essay, "The Rational and the Reasonable," by noting that while the two terms 'rational' and 'reasonable' both designate "a conformity with reason" (Perelman 1969a, 117), they cannot be used interchangeably and therefore cannot be synonymous. According to Perelman, in order to account for this lack of synonymy, it must be that the terms 'rational' and 'reasonable' indicate two different ways of conceptualizing reason. Perelman accounts for this difference by distinguishing between the rational and the reasonable in terms of their relation to truth and their method. What is rational seeks necessary truths and so favors demonstration, while what is reasonable aims for the probable, the acceptable and as such, requires argumentation.

Perelman writes that "from a traditional point of view, philosophical discourse is discourse addressed to reason, the latter being considered a faculty illuminated by divine reason or at least modeled on it-a non-temporal and invariable faculty, common to all rational beings, and constituting the specific characteristic of all members of the human race" (Perelman 1969b, 47). Philosophical discourse understood this way aims for universal, abstract truths, apprehensible to all those that possess the faculty. "The rational corresponds to mathematical reason ... which grasps necessary relations, which knows a priori certain self-evident and immutable truths" (Perelman 1969a, 117). What is discoverable by reason "owes nothing to experience or to dialogue, and depends neither on education nor on the culture of a milieu or an epoch" (ibid, 117). Universality, necessity and selfevidence become the hallmarks of the rational. What is rational is what anyone who reflects would come to conclude, independently of other inquirers. The method of demonstration and deduction of conclusions from self-evident propositions then becomes the height of rationality. Through the analysis of the proofs used in mathematics, "modern formal logic became...the study of the methods of demonstrations used in the mathematical sciences" (Perelman and Olbrechts-Tyteca 1969, 10 ). Arguments are reduced to a series of statements, one of which is the conclusion. The validity of an inference from the premises to the conclusion is decided by rules of inference, and the validity of an argument is decided in virtue of form alone. It is not difficult to see how modern formal logic seems to embody the character of the rational; once accepting the rules of inference and argument forms that are valid for a system, it is possible for any inquirer to see the necessity in the link from premises to conclusion.

For Perelman, "it is the idea of self-evidence as characteristic of reason, which we must assail, if we are to make place for a theory of argumentation that will acknowledge the use of reason in directing our own actions and influencing those of others" (ibid., 3). We need to extend the concept of reason to include the 
method of justification in addition to demonstration, and understand truth in terms of the probable in addition to the certain if we are to say we argue rationally. What Perelman seeks to show is that in debate and argumentation there is rationality to be found.

Perelman, then, contrasts the rational against the reasonable by virtue of a truth criterion-self-evidence versus acceptability -as well as by virtue of methodwhat all beings can arrive at upon private investigation versus what it makes sense to believe given our community of beliefs. That is, what we can provide justification for on the basis of information at our disposal. Most importantly, what is considered to be reasonable is reasonable given a context. The reasonable man does not strive for abstract universality but is one "who in his judgements and conduct is influenced by common sense" (Perelman 1969a, 118). What is reasonable conforms to a time and a place: "The reasonable of one age is not the reasonable of another: it can vary like common sense" (ibid, 119). The reasonable can vary because it does not aim for absolute truth, but rather what is acceptable to the community. What is reasonable is not certain, and cannot be determined independently of context or independently of other minds and as such, other opinions to consider or react against. Where we must choose between opinions, where the object of inquiry is not self-evidently true, and therefore where deductions have no place, we are out of the realm of the rational as it has been traditionally conceived. "The very nature of deliberation and argumentation is opposed to necessity and self-evidence, since no one deliberates or argues against what is self-evident" (Perelman and Olbrechts-Tyteca 1969,1). The reasonable is not the domain of Truth, but rather of acceptability. "The domain of argumentation is that of the credible, the plausible, the probable to the degree that the latter eludes the certainty of calculations" (ibid, 1). The reasonable, then, presents a different kind of ideal than the rational.

Rationality in argumentation is constituted by the reasonable. Because it is not possible to argue about what is certain, what is rational in argumentation is to aim for acceptability. What will be accepted by an audience is a function of its situation in the world, its experiences and belief systems, as well as historical and contextual considerations. What will be considered reasonable to an audience will be a function of its beliefs and experiences, the knowledge it possesses. It should be noted that what makes up the realm of the reasonable, itself may arise out of the practice of argumentation. However, what we come to decide may not be valid for those outside our context, nor remain valid for our context indefinitely. The reasonable allows for an understanding of rationality that is flexible and plastic, one that affords the appeal to our circumstance as a necessary, 'rational' appeal. Perelman's theory of argumentation reflects this plasticity and this conception of rationality in argumentation.

According to Perelman, "the object of the theory of argumentation is the study of the discursive techniques allowing us to induce or to increase the mind's adher- 
ence to the theses presented for its assent" (ibid.,4). The adherence of a mind to a thesis can be of a greater or lesser intensity, as determined by the individual mind that adheres. The audience plays an important role in The New Rhetoric because argumentation is always directed to an audience for their acceptance or rejection. What I would like to stress at this point is that any audience is not a passive recipient of the arguments and information presented. We can be assured that the audience already holds some attitudes or beliefs, which will certainly play a role in what they will come to accept. However, the speaker must write or construct her or his argument before facing the audience. As such, "the audience... is always more or less a systematized construction" (ibid., 19) of the speaker, who must imagine who his actual or potential listeners might be. In order for argumentation to be successful, "care must be taken to form a concept of the anticipated audience as close as possible to reality" (ibid, 20). If the goal of argumentation is to increase the mind's adherence to theses presented to it, "it is indeed the audience which has the major role in determining the quality of argument" (ibid., 24). What is rational in argumentation is a function of the audience. Who the audience is determines the quality of the arguments offered in that argumentation should always be appropriate.

Where the subject matter is not one that admits to certain judgements (and so can be resolved by the rational means of deduction), we are left with the realm of reasonableness. What will count as reasonable from inquirer to inquirer, and from audience to audience, may vary. Each community may have a different standard of reasonableness and each audience will require that its own standard of reasonableness be met. What this conception of reasonableness offers to Johnson's theory is a way of construing the dialectical tier as a rational component of argumentation. The objections and opposing points of view considered in the dialectical tier are required to relate to the audience's standard of reasonableness. That many points of view be discussed is not necessary. What is responded to will be a function of the audience being addressed. The dialectical tier must appeal to the contextual and historical concerns of the audience, to common sense or common knowledge relative to the issue at hand. The point to make is that appeal to these standards of reasonableness, appeal to common knowledge, is a rational appeal.

The standard of reasonableness appears, at first glance, to offer very little by way of guidance in what to include or exclude as part of the dialectical tier. However, in composing an argument the author is in a position to know what is held to be common knowledge and of what alternative positions there are concerning any given issue. We might understand what is reasonable given the topic of discussion, or the anticipated level of expertise of the audience. Operating with Perelman's conception of reasonableness, it is possible to avoid Johnson's counter-intuitive claim that in order for an argument to count as rational, it must address even objections and alternative positions that are 'known to be misguided'. With Perelman in hand, it is possible to now say that the argument must address those objections 
and aiternative positions that are known to be misguided by the arguer, but that the audience may still hold. If both the arguer and audience believe some objections and alternative positions to be misguided, then it is perfectly rational to exclude them. What Perelman's conception offers is a way of understanding the appeal to common knowledge, that is the knowledge of the audience on a given topic, as a rational appeal.

Given Perelman's conception of reasonableness, the inclusion of the dialectical tier is necessary for an argument to count as rational because it takes into account the likely position of the audience, positions which are a function of their context, which are themselves reasonable. If the very nature of argumentation is understood in terms of Perelman's conception of reasonableness, in terms of acceptability, then we can include the dialectical tier as a necessary component of rational argumentation as responding to what the audience may already consider acceptable, or reasonable. If argumentation, in order to be a rational activity must take as its domain that of the reasonable, then appeal to this domain of common knowledge, of the anticipated position of the audience with respect to the issue at hand, is a rational appeal. The dialectical tier is an essential component of a rational argument because it appeals in content to the realm of the reasonable, the mode in which argumentation is rational.

\section{Normative Issues and Concluding Remarks}

Perhaps the most serious objection to the above analysis is that I have failed to mention the normative criteria for argument evaluation offered in Manifest Rationality. After all, Johnson stipulates that in order for an argument to achieve the goal of rational persuasion, it must meet the normative criteria identified for both the illative core and the dialectical tier. On this note, it seems strange to turn to Perelman's work for illumination, given that he does not provide any criteria for argument evaluation. So what, exactly, am I doing here?

The importance I assign Perelman's work has to do with his conception of how argumentation itself is rational, and that argumentation gains the character of rationality by appeal to the audience. I use Perelman's ideas as a way to provide a further justification of Johnson's claims. With Perelman's richer conception of rationality in argumentation, it is possible to provide a grounding for even the normative criteria for the illative core and the dialectical tier. Briefly, the criteria for the illative core are the requirements of acceptability, truth, relevance and sufficiency. The dialectical tier must satisfactorily deal with objections, the consequences or implications of the illative core, as well as address alternative positions. In the discussion of these criteria, it becomes clear that they are for the most part dialectical in nature, and so do make the audience an integral component to making a rational product. However, it seems to me that we should be able to account for the necessity of each requirement in terms of the conception of rationality at work in the theory. That is, the normative criteria for the product of argumentation 
should ensure a more rational product because they draw upon the conception of rationality in operation. My suspicion is that given Johnson's current specification of rationality, it will not be possible to do so. However, if we were to supplement Johnson's structural view of rationality with a more contextualized view of rationality like Perelman's, it will be possible to do so.

Johnson has claimed that "the theory of appraisal should be based on the theory of analysis" (Johnson 2000, 143). My position today is that in order for the dialectical tier to be accepted as a necessary component of a rational product of argumentation, we need to take the analysis a step further and so adopt a richer, contextual sense of rationality that echoes the standard of reasonableness as Perelman has conceived it.

\section{Note}

'Johnson admittedly bypasses theoretical issues concerning rationality and states that "rationality can be understood as the disposition to, and the action of, using, giving, and/or acting on the basis of reasons" (Johnson 2000, 161)

\section{References}

Hitchcock, David. 2002. "The Practice of Argumentative Discussion", Argumentation 16:287-298.

Johnson, Ralph H. 2000. Manifest Rationality: A Pragmatic Theory of Argument. Mahwah, NJ: Lawrence Erlbaum Associates.

Leff, Michael. 2000. "Rhetoric and Dialectic in the Twenty-first Century." Argumentation 14: 241-254.

Perelman, Chaïm. 1969a. "The Rational and the Reasonable." In Chaim Perelman, The New Rhetoric and the Humanities: Essays on Rhetoric and its Applications. London: Reidel.

- 1969b. "Rhetoric and Philosophy". In Chaim Perelman, The New Rhetoric and the Humanities: Essays on Rhetoric and its Applications. London: Reidel.

Perelman, Chaïm and Lucy Olbrechts-Tyteca. 1969. The New Rhetoric: A Treatise on Argumentation. Wilkinson, J. \& Weaver, P., trans. University of Notre Dame Press.

Amy Ohler

Department of Philosophy

McMaster Universily

Hamilion, ON, Canada L8S 4KI 